\title{
LAS RELACIONES ENTRE EL DERECHO INTERNACIONAL Y EL DERECHO INTERNO: EL CASO DE LA CONSTITUCIÓN. LA CONSTITUCIÓN COMO FUENTE DE DERECHO INTERNACIONAL
}

GONZALO M. QUINTERO SARAVIA 



\section{LAS RELACIONES ENTRE EL DERECHO INTERNACIONAL Y EL DERECHO INTERNO: EL CASO DE LA CONSTITUCIÓN. LA CONSTITUCIÓN COMO FUENTE DE DERECHO INTERNACIONAL (*)}

POR

GONZALO M. QUINTERO SARAVIA

\section{LAS RELACIONES ENTRE LA CONSTITUCIÓN Y EL DERECHO INTERNACIONAL DEBEN SER REGIDAS POR EL PRINCIPIO DE COMPETENCIA Y NO POR EL DE JERAROUÍA}

El problema de cómo deben regularse las, no siempre sencillas, relaciones entre el Derecho interno y el Derecho internacional se ha planteado desde el mismo momento del nacimiento de ambos Orde-

(*) El presente artículo está basado en las conclusiones finales de la tesis doctoral presentada en la UNED bajo la dirección del catedrático $D$. Antonio Torres del Moral sobre las relaciones entre el Derecho internacional y el Derecho interno, más concretamente con la Constitución. De esta manera el presente estudio se encuentra a caballo de dos disciplinas jurídicas que tienen, cada una de ellas, rasgos y características bien diferenciados. Tanto el Derecho internacional como el Derecho constitucional son campos doctrinales suficientemente bien delimitados, pero que adolecen de un cierto aislamiento en su consideración. Aislamiento que hemos pretendido romper, observando la Constitución desde una perspectiva nueva, la de su cara internacional. 
nes. Las respuestas que se han dado van, desde el Monismo', para el que todos los ordenamientos forman parte de uno sólo, en cuyo vértice se encontraría el Derecho internacional, hasta el Dualismo², que postula la separación entre ordenamientos; pasando por toda una serie de posturas coordinadoras o eclécticas ${ }^{3}$ que buscan encontrar un justo medio. Pero lo que aquí hay que destacar es cómo los órdenes interno e internacional se necesitan mutuamente, y para ello nada mejor que remitirnos a la práctica diaria en la que se dan multitud de casos en los

1 La base de todas las doctrinas dualistas se encuentra en la obra monumental de KeLSEN (La transformation du Droit International en Droit interne, 1936; "Les rapports de système entre le Droit interne et le Droit International", Recueil des Cours de l'Academie de Droit International de la Haye, IV, vol. 14, 1926, págs. 227 y sgtes.), quien entendía que la validez y la fuerza obligatoria de cada norma jurídica deriva de otro tipo de normas jerárquicamente superiores. Así se establece una cadena en la que las normas van otorgando validez a las que se encuentran en un escalón inferior, así hasta llegar a aquella que se constituye como "grundnorm". Esta "grundnorm" terminó situándola KELSEN, en su evolución, en el campo del Derecho internacional. En 1926, KELSEN mantenía que esta grundnorm bien podía situarse en el campo del Derecho internacional o en el del Derecho interno, dependiendo de toda una serie de factores éticos o políticos. Posteriormente evolucionó hasta los postulados que acabamos de exponer. En este contexto fue Verdross ("Le Fondement du Droit International', Recueil des Cours de l'Academie de Droit International de la Haye, vol. 16, 1927, págs. 257 y sgtes.), discípulo de KELSEN, quién mantuvo que la norma normarum que sustentaba la validez del resto del ordenamiento se encontraba en el Derecho internacional, y que era éste quién delegaba en los Estados una "determinada competencia legislativa en favor de los Estados», en palabras de PASTOR RIDRUeJo (Derecho Internacional Público y Organizaciones Internacionales, Madrid, 1989, págs. 175 y 176).

2 Así Triepel (Völkerrecht und Landesrecht, 1899) sustenta toda su exposición en dos presupuestos previos. Por una parte, sostiene que el Derecho internacional y el Derecho interno son esencialmente distintos y que consecuencia de ello es que tienen distintas fuentes. El segundo postulado, conectado intimamente con el anterior, es que, mientras que el Derecho internacional tiene por objeto el regular las relaciones entre Estados, el Derecho interno lo hace con las existentes entre individuos, o también entre el Estado en cuanto que poder, con sus ciudadanos.

3 Todo este conjunto de posturas coordinadoras, tienen un presupuesto en común que es el partir de un substrato monista, al considerar que, tanto las normas de Derecho interno como las de Derecho internacional comparten esencialmente una misma naturaleza, las doctrinas coordinadoras, en su intento de superar el callejón sin salida producido por la oposición entre el dualismo y el monismo, no hablan de subordinación de los distintos Derechos internos con respecto al Derecho internacional, sino que pasan a considerar una relación de coordinación entre uno y otro ordenamiento. Tal coordinación deberá realizarse sobre la base de una serie de normas que son efectivamente superiores a los dos ordenamientos, el interno y el Internacional. Estas normas superiores serian las de Derecho Natural. 
que uno se remite al otro y viceversa. Es dentro de este contexto general donde tradicionalmente se han estudiado las relaciones entre el Derecho internacional y la Constitución. $Y$ es precisamente dentro de este tipo de análisis tradicional donde surgen las tensiones. Un ejemplo perfecto de estas tensiones son las existentes entre el Derecho primario de la Unión Europea y las constituciones de los distintos Estados miembros, donde lo que busca la Unión Europea es la imposición de su ordenamiento a través de la figura de la primacía ${ }^{4}$.

Como ilustración de ello baste recordar el caso de Alemania. El Tribunal Constitucional alemán siempre se ha mostrado extremadamente puntilloso en lo que se refiere al respeto y a las garantías de los valores contenidos en el estado democrático de derecho, es decir la democracia y los derechos y libertades fundamentales. Para éstos últimos, el tribunal alemán, en sus sentencias Solange $\|{ }^{5}$ y Soweit ${ }^{6}$, si bien admite que la jurisprudencia y la práctica comunitarias aplican y protegen estos derechos se reserva el derecho de verificar la constitucionalidad de las normas comunitarias en caso que la protección ofrecida por la Unión Europea, y más concretamente por el Tribunal de Justicia de Luxemburgo, se mostrase, a su juicio, insuficiente. Para la garantía del principio democrático, el Tribunal Constitucional alemán en su sentencia de 12 de octubre de 1993, manifiesta que es, precisamente, la garantía del mantenimiento de este principio la que limita posibles transferencias a la Unión Europea y lo que hace, y obliga a que los Estados retengan garantías para ello a través de los Parlamentos Nacionales.

Esta colisión entre la defensa de las constituciones de los Estados miembros y el desarrollo normativo del Derecho comunitario llegó a su

4 El origen de este principio se encuentra en las sentencias del Tribunal de Justicia de Luxemburgo Costa/ENEL (15 de julio de 1964, Colección, 1964, págs. 1141 y sgtes.) y Simmenthal (Asunto 106/77, Colección, 1978, págs. 629 y sgtes.), es en esta última donde expresamente se dice en su considerando num. 17, "estas disposiciones y actos forman parte integrante, con rango de prioridad, del ordenamiento jurídico aplicable en el territorio de los Estados miembros". Esta afirmación es llevada por el Tribunal de Justicia de Luxemburgo hasta sus últimas consecuencias cuando mantiene este principio de primacía del ordenamiento comunitario sobre la totalidad de los ordenamientos de los Estados miembros, con lo que se entiende que queda consagrada la primacía sobre las constituciones de éstos.

5 Sentencia del Tribunal Constitucional de Alemania en el caso Solange II, de 22 de octubre de 1986.

6 Sentencia del Tribunal Constitucional de Alemania en el caso Soweit, de 12 de mayo de 1989. 
máxima expresión a la hora de confrontar las disposiciones contenidas en el Tratado de la Unión Europea con las constituciones de los Estados miembros. Tras su aprobación el 7 de febrero de 1992 se inició un proceso de ratificación no exento de problemas. Como por ejemplo el caso danés, donde el 2 de junio de 1992 se celebró un referendum para someter a aprobación la ratificación por parte de Dinamarca del tratado de la Unión Europea, con el resultado de una respuesta negativa. Lo que llevó al gobierno danés a aclarar, o al menos intentarlo, su relación con el resto de los Estados miembros y con la misma Unión Europea, cosa que hizo a través de un documento que presentó el 30 de octubre del mismo año por el que fijaban los parámetros de estas relaciones. Entre otras cosas hay que destacar que Dinamarca solamente será observador en la Unión Europea Occidental, que no participará en la tercera fase de la unión económica y monetaria ni en la futura moneda única, que la ciudadanía europea operará de manera muy limitada para los ciudadanos daneses, etc... Pero lo que aquí resulta relevante es cómo los ordenamientos internos fueron dando distintas soluciones al problema de la compatibilidad constitucional del tratado de Maastricht. Ante ello se plantearon lo que Muñoz Machado ${ }^{7}$ denomina como tres modelos diferentes.

EI PRIMERO es el que estipulaba que la ratificación no implicaba modificación constitucional alguna, como sucedió en Bélgica y en Holanda, donde hay una tradición constitucional que incorpora directamente los tratados internacionales al ordenamiento interno. Este también fue el caso de Gran Bretaña que, al no tener constitución en sentido formal, le bastó con la aprobación por parte del Parlamento de una Ley que modificase la anterior European Communities Act de 1972.

EI SEGUNDO de los modelos es el que establece la necesidad de una reforma de mínimo alcance, como el caso de Luxemburgo y España. En esta última se produjo la modificación del artículo 13.2. de la Constitución Española de 1978 por el que se amplía el derecho de sufragio pasivo en las elecciones municipales a los ciudadanos comunitarios residentes en España ${ }^{8}$, para hacerlo compatible con la nueva redacción del artículo 8 b). 1. del tratado CEE. drid, 1994.

7 Muñoz Machado, S., La Unión Europea y las mutaciones del Estado, Ma-

8 Constitución española de 1978, modificada por Reforma constitucional de 27 de agosto de 1992 (Boletín Oficial del Estado de 28 de agosto), artículo 13, apartado segundo, "Solamente los españoles serán titulares de los derechos reconocidos en el artículo 23, salvo lo que, atendiendo a criterios de reciprocidad, pueda establecerse por tratado o ley para el derecho de sufragio activo $y$ pasivo en las elecciones municipales". 
Por último se encuentra el TERCER MODELO, formado por aquellos Estados en los que se estimó que Maastricht producía un serio impacto constitucional. Éste resulta ser el más interesante por ser el más revelador de las tensiones Constitución-Derecho comunitario, por lo que lo estudiaremos con cierta profundidad. Antes de nada, hay que acudir al concepto de las "mutaciones constitucionales". La doctrina de las mutaciones constitucionales fue creada por JELLINEK ${ }^{9}$, y enfrenta este concepto al de reforma constitucional. Mientras que en la reforma constitucional hay una modificación o alteración clara de la letra y el espíritu de la Constitución, que se plasma en el seguimiento de una serie de cauces predeterminados, en el caso de la mutación constitucional sucede algo que termina en una modificación o alteración pero por una via distinta. En la mutación constitucional hay una transformación que puede ser de enorme alcance pero sin mediar reforma constitucional alguna. Estas modificaciones se producen por lo que el propio JELLINEK ${ }^{10}$ llamaba "la fuerza normativa de lo fáctico". Es importante tener en consideración esta figura, ya que el verdadero alcance de las reformas del tratado de Maastricht introduce criterios que sin hacer demasiados aspavientos, pero de una manera sólida, van modificando el sutil equilibrio entre instituciones y poderes que determinan las distintas constituciones de los Estados miembros. Siguiendo con el grupo de países que han abordado la cuestión de una reforma constitucional razonablemente amplia encontramos dos casos señalados, Francia y Alemania.

El caso de Francia: aquí es especialmente relevante la decisión de su Consejo constitucional de 9 de abril de $1992^{11}$, en la que respondiendo a una consulta del Presidente de la República determinó que la regulación de ciertas competencias por parte del tratado de Maastricht "ponen en cuestión las condiciones esenciales del ejercicio de la soberanía nacional», por lo que establecía como indispensable una amplia reforma constitucional. Esta llegó a través de la Ley constitucional de 25 de junio de 1992 que añade a la Constitución francesa de 4 de octubre de 1958 un título llamado "de las Comunidades Europeas y de la Unión European, con el que quedan solventados los problemas mencionados a través de una redacción muy amplia. Establece el artículo 88.1. de esta ley constutucional de 25 de junio de 1992 que, "la Repú-

9 JelLineK, G., Verfassungsänderung und Verfassungswandlung, Berlín, 1906. Traducción española, Reforma y Mutación de la constitución, Madrid, 1991.

10 Jellinek, G., Teoría General del Estado, Buenos Aires, 1978.

11 Desition du Conseil Constitutinnel 92/308, de 9 de abril de 1992. 
blica participa en las Comunidades Europeas y en la Unión Europea, constituidas por Estados que han escogido libremente, en virtud de los Tratados que las han instituido, ejercer en común algunas de sus competencias". También en Francia se planteó algo que será esencial para el caso alemán como es el necesario incremento de la legitimación democrática de la Unión Europea. Para ello se incorporó un cuarto apartado a este artículo 88 en el que se garantiza la participación de la Asamblea Nacional francesa y de su Senado, en aquellas proposiciones comunitarias que supongan disposiciones de naturaleza legislativa.

En cuanto al caso alemán, también se hizo necesaria una adecuación constitucional de la Ley Fundamental de Bonn de 23 de mayo de 1949 a través de una reforma constitucional plasmada en la Ley de Reforma de 21 de diciembre de 1992, que entre otras modificaciones estableció una nueva redacción para el artículo 23.1. que queda redactado así: "Para hacer realidad una Europa unida, la República Federal de Alemania contribuirá al desarrollo de la Unión Europea, dentro de su compromiso con los principios democráticos del Estado de Derecho, sociales $y$ federales, y con el principio de la subsidiariedad y de garantizar una protección de los derechos fundamentales comparable en lo esencial a la de esta Ley Fundamental. Para ello la Federación podrá transferir derechos de soberanía por ley que cuente con el consentimiento del Consejo Federal. Para lo relativo a la Constitución de la Unión Europea, así como a las modificaciones de sus tratados básicos y reglamentaciones análogas, en virtud de los cuales esta Ley Fundamental resulte modificada o adicionada en su contenido o bien se hagan posibles tales modificaciones o adiciones, será aplicable lo dispuesto en el artículo 79, párrafos 2 y 3 "».

En definitiva, hay que considerar que el consentimiento de Alemania para ratificar Maastricht, y para formar parte de la Unión Europea, es el del mantenimiento de los principios esenciales del Estado democrático de derecho. Se trata de la explicitación de una de las tesis fundamentales que aquí mantenemos: que el ser un Estado democrático de derecho supone que en la esfera internacional a la hora de contratar, o lo que es lo mismo a la hora de concluir tratados internacionales el Estado se encuentra limitado por esta concepción de sí mismo. Y es en este mismo sentido en el que abunda la sentencia del Tribunal Constitucional alemán de 12 de octubre de 1993, que deja bien claras dos cosas. Por un lado, que no son posibles las remisiones en bloque o las autorizaciones en blanco a la Unión Europea cuando dice que: "Se vulnera el artículo $\mathbf{3 8}$ de la Ley Fundamental si una ley que abre el ordenamiento jurídico alemán a la vigencia y aplicación di- 
recta del derecho de las Comunidades Europeas -supranacionales- no define suficientemente los derechos cedidos para su ejercicio y el programa de integración previsto" ${ }^{12}$. Por otro lado deja bien sentado que en el momento presente las instituciones comunitarias, en concreto el Parlamento Europeo, no representa a un pueblo de Europa sino a los pueblos de los Estados miembros ${ }^{13}$ con lo que para salvaguardar la legitimación del principio democrático la Dieta Federal debe retener el control sobre la Unión para asegurar la exigencia del respeto a la democracia que impone su Ley Federal. Ello queda perfectamente patente cuando dice que, "(...) la norma democrática no impide a la República Federal de Alemania adherirse a una comunidad interestatal que esté organizada con criterios supranacionales. Sin embargo, esta adhesión exige que se garanticen una legitimación y una influencia emanadas del pueblo incluso dentro de la confederación de Estados" ${ }^{14}$. $Y$ al no poder hacerse ello a través del Parlamento Europeo del que dice que tiene, "una función esencialmente consultiva" ${ }^{15}$ determina que la, "(...) legitimación democrática tiene lugar, pues, en virtud de la conexión (sic) de la actuación de los órganos europeos con los Parlamentos de los Estados miembros" ${ }^{16}$. Y concluye de un modo rotundo al decir que, "(...) si son -como en el presente- los pueblos de los Estados quienes a través de los Parlamentos nacionales, procuran la legitimación democrática, ello supone que a la expansión de tareas y atribuciones de las Comunidades Europeas le pone coto el principio democráticon" ${ }^{17}$.

En definitiva, que toda transferencia a otro ordenamiento, en este caso al Derecho de la Unión Europea, debe entenderse hecha sin menoscabo del respeto de los derechos y libertades fundamentales $y$, en todo caso, bajo condición de respetar también el principio democrático. Además, no hay que olvidar la importancia que reviste el que

12 Sentencia del Tribunal Constitucional alemán de 12 de octubre de 1993, (directriz jurisprudencial número 5), publicada en el Boletín de Jurisprudencia Constitucional número 153 (1994).

13 Tratado de Roma, artículo 137.»El Parlamento Europeo compuesto por representantes de los pueblos de los Estados reunidos en la Comunidad, ejercerá las competencias de deliberación y de control que le atribuye el presente Tratadon.

14 Sentencia del Tribunal Constitucional alemán de 12 de octubre de 1993, (C-I-2-b), Boletín de Jurisprudencia Constitucional, núm. 153 (1994).

15 Sentencia del Tribunal Constitucional alemán de 12 de octubre de 1993, (A-II-1.a.párrafo 2), Boletín de Jurisprudencia Constitucional núm. 153 (1994).

16 Sentencia del Tribunal Constitucional alemán de 12 de octubre de 1993, (C-1-2-b.2), Boletín de Jurisprudencia Constitucional núm. 153 (1994).

17 Idem que la nota anterior. 
sean precisamente Francia y Alemania quienes hayan dejado tan clara su postura, ya que siempre se ha considerado a estos países como el tándem de locomotoras que dirigía la Comunidad.

Por ello, pese a que el Derecho comunitario se esfuerce en mantener su primacía sobre todas y cada una de la constituciones de los Estados miembros, los procesos de ratificación del tratado de la Unión Europea han dejado claro que las relaciones entre los ordenamientos interno y comunitario distan mucho de poder ser exclusivamente reguladas por este principio. Además, mantener la absoluta primacía del Derecho comunitario sobre las constituciones de los Estados miembros, nos parece a nosotros particularmente absurdo, y que va a contrapelo de todos y cada uno de los principios en los que está basado el Estado democrático de derecho. Esta idea colocaría por encima de la decisión del pueblo soberano la voluntad emanada de una serie de organismos de los que lo más caritativo que se puede decir es que tienen un serio déficit democrático. Este déficit democrático es un viejo problema de la Unión Europea derivado del origen no electivo de sus distintas instituciones, y una prueba de la pervivencia de este problema está en que en las propias conclusiones de la Presidencia española del Consejo Europeo de Madrid, 15-16 de diciembre de 1995, se recoge en su anexo 15 como una de las prioridades de la Conferencia Intergubernamental, el mejorar la democracia dentro de la propia Unión, en el sentido de asegurar úna representación justa dentro de las distintas instituciones y de reforzar el papel a desempeñar por la única institución realmente democrática de la Unión, el Parlamento Europeo, y por los distintos Parlamentos de los Estados miembros.

En definitiva y por medio del recurso de la reducción al absurdo, mantener que una Directiva que establezca los precios de la patata temprana, que emana de un servicio de una Dirección General de la Comisión, tenga un rango superior al de la Constitución Española de 1978 , aprobada en referendum por el pueblo soberano, es una idea que repele, no solamente a todo iuspublicista, sino también, a toda persona razonable.

De nuevo parece procedente reconducir hacia nuevos terrenos la, a veces incluso casi sangrienta, polémica entre autores "nacionales" y autores "comunitarios", o lo que es su reflejo en el mundo de la judicatura: entre los Tribunales, bien Supremos bien Constitucionales ${ }^{18}$,

18 Dependiendo del tipo de órgano que esté encargado por su respectiva Constitución de velar por el cumplimiento de la misma. 
de los Estados miembros de la Unión Europea y el Tribunal de Justicia de las Comunidades Europeas. Se trata de cambiar las ideas preconcebidas que se tienen sobre los principios que deben gobernar las relaciones entre ordenamientos. Así, hay que abandonar el hábito de pensar en términos de jerarquía, para pasar a concebir las relaciones entre el Derecho emanado de la Unión Europea y los Derechos internos de los Estados miembros en términos de competencia. La estructuración de los ordenamientos en torno a las ideas de jerarquía se deriva de una concepción del Derecho que, hoy por hoy, debe ser abandonada. La primacía comunitaria nace en un momento en el que las instituciones comunitarias necesitaban imponerse sobre las regulaciones internas para poder ser eficaces, pero este afán invasor y globalizador del Derecho comunitario debe entenderse como perteneciente al pasado. Desde el Consejo Europeo de Edimburgo ${ }^{19} \mathrm{y}$, sobre todo, desde lo dispuesto por el nuevo artículo $3 \mathrm{~B}$ del tratado CEE introducido por el tratado de la Unión Europea ${ }^{20}$, existe un principio esencial dentro de toda la actuación de la Unión que es el de Subsidiariedad. El contenido esencial de este principio de Subsidiariedad es que busca resolver los problemas en el nivel más cercano al ciudadano y que solamente se transfiere la competencia o el ejercicio de ésta a un nivel superior, si, y sólo si, el inferior no puede cumplir adecuadamente con ella. Este artículo 3B, dice taxativamente que, "La Comunidad actuará dentro de los límites de las competencias que le atribuye el presente Tratado y de los objetivos que éste le asigne. En los ámbitos que no sean de su competencia exclusiva, la Comunidad intervendrá conforme al principio de subsidiariedad, sólo en la medida en que los objetivos de la acción pretendida no puedan ser alcanzados de manera suficiente por los Estados miembros, y, por consiguiente, puedan lograrse mejor, debido a la dimensión o a los efectos de la acción contemplada, a nivel comunitario. Ninguna acción de la Comunidad excederá de lo necesario para alcanzar los objetivos del presente Tratado".

Esta idea de subsidiariedad viene a complementar el desplazamiento del principio de jerarquía por el de la competencia para determinar y vertebrar las relaciones entre los órdenes comunitario e interno. De esta manera una disposición comunitaria sobre la patata temprana no se impone jerárquicamente sobre la Constitución, sino

19 Consejo Europeo de Edimburgo celebrado los días 11 y 12 de diciembre de 1992.

20 Tratado de la Comunidad Económica Europea, modificado por el tratado de la Unión Europea, hecho en Maastricht el 7 de febrero de 1992. 
que se aplica preferentemente debido a la especialidad y a la competencia de la autoridad que la dictó para hacerlo. Esta competencia de la autoridad de la Unión Europea vendrá determinada por toda una serie de reglas, de entre las cuales destacan también las propias constituciones de los Estados miembros.

\section{PRECISIONES SOBRE EL CONCEPTO DE CONSTITUCIÓN}

Ya en el mismo momento de tener que determinar qué concepto de Constitución se debe de manejar en un estudio que constantemente pone en relación los órdenes interno e internacional surgen las tensiones entre el Derecho constitucional $y$ el Derecho internacional. Mientras éste último tiene una esencial vocación de universalidad, en el Derecho constitucional priman otra serie de consideraciones substantivas. Dicho de otro modo, el peligro del Derecho internacional es la vaciedad y el del Derecho constitucional es el localismo. Ante esta disyuntiva, se impone elegir un concepto de Constitución que respete la esencia del Derecho constitucional y a la vez sea susceptible de ser "comparado" o "extrapolado" de un Estado a otro. Aquí hemos de reconocer que hemos primado ciertos criterios constitucionalistas a la hora de dotar a la constitución de un contenido de valores substantivos fundamentales. Al hacer esta elección hemos sido plenamente conscientes de la reducción del ámbito de nuestro trabajo, ya que solamente así las constituciones de los Estados realmente constitucionales serían fuente del Derecho internacional, operar de otro modo no hubiera sido ni riguroso ni honesto.

Asi las cosas, hemos recurrido a la exposición de un concepto que contiene los que consideramos, de acuerdo con la mayoría de la doctrina constitucionalista moderna, son los requisitos esenciales de una verdadera Constitución. Así, se llega a lo que se ha denominado como un concepto de trabajo de Constitución, ya que el concepto definitivo no se puede dar hasta la incorporación de los elementos internacionales, que más adelante señalamos. Este concepto de trabajo de Constitución queda como "Lea selección de las normas jurídicas ${ }^{21}$

${ }^{21}$ Expresa su intención de autoregular, por esas mismas bases, el proyecto de futuro común. Recurriendo a la idea de la "positividad» de DE OTTo (Derecho Constitucional. Sistema de fuentes, Barcelona, 1991. Pág. 21), al haber manifestado que una característica de los ordenamientos jurídicos modernos es la idea de 
superiores ${ }^{22}$ que contienen la organización institucional esencial ${ }^{23} \mathrm{del}$ Estado y por las que este Estado se configura como un Estado democrático $^{24}$ de derech ${ }^{25}$ ").

Con lo que la primera y evidente consecuencia es que no todos los Estados tiene una verdadera Constitución. Mientras que en el contexto del Derecho internacional se habla de las constituciones de los Estados como si fuesen iguales, como si tuviesen el mismo valor todas y cada una de ellas, de la misma manera que para él son absolutamente iguales todos y cada uno de los Estados que forman la comunidad internacional. Pero si desde aquí se ha adoptado lo que se ha denominado como un concepto substantivo de constitución, esta absoluta igualdad y equivalencia entre Estados y sus constituciones ya no son válidas. De esta manera para nuestro análisis habrá multitud de Estados que no tengan Constitución pese a que ellos mismos insistan en denominar de esta manera a su ley o leyes fundamentales.

positividad, por la que se institucionalizan los mecanismos de cambio. La distinción entre sistemas antiguos y modernos es precisamente su actitud frente a este cambio, se "(...) establece una diferenciación estructural entre la desobediencia y el cambio (sic), lo que no ocurría en la sociedad tradicional».

22 Garcia de ENTERRIA (La Constitución como norma y el tribunal constitucional, Madrid, 1985. Pág. 49) cuando señala que, "la constitución no sólo es una norma, sino precisamente la primera de las normas del ordenamiento entero, la norma fundamental, lex superior (sic). Primero, porque la constitución define el sistema de fuentes formales del Derecho, (...) Segundo, porque en la medida en que la Constitución es la expresión de una intención fundacional, configuradora de un sistema entero que en ella se basa, tiene una pretensión de permanencia (...) o duración".

${ }^{23}$ Este elemento aunque esencial, no se halla cargado de contenido doctrinal, sino que es una parte descriptiva del contenido, y se puede rastrear en las más antiguas concepciones de Constitución, como las de ARISTóteles (Ética a Nicómaco. Traducción de M. Araujo y J. Marias, Madrid, 1959) o del llamado Pseudo-Jenofonte (La constitución de los atenienses, traducción de M. Fernández Gallano, Madrid, 1951).

24 Como dice Rubio LloRente ("La Constitución como fuente del Derecho", artículo incluido en el libro colectivo, La Constitución española y las fuentes del Derecho, 1979, vol. I, pág. 61), "Por Constitución entendemos... y entiende hoy lo mejor de la doctrina, un modo de ordenación de la vida social en el que la titularidad de la soberania corresponde a las generaciones vivas... (...). No hay otra Constitución que la Constitución democrática».

${ }_{25}$ Para que se pueda hablar de un Estado como Estado de derecho es necesario que en él se reconozcan y respeten los derechos y libertades fundamentales. Separación de poderes. El fin de esta separación de poderes no es otro que asegurar el control y la limitación del ejercicio del poder. La ley como valor. Que se desdobla en dos ámbitos, por un lado el imperio de la ley, y por otro el principio de legalidad. 
De este modo, superado el concepto tradicional de constitución, en el que únicamente se tienen en cuenta los aspectos relevantes para el Derecho interno, podemos formular la siguiente definición que incorporará su nueva dimensión internacional.

Constitución es "aquel/los acto/s unilateral/es escrito del Estado, por el que (o por los que) este Estado establece los principios del Estado democrático de derecho como rectores de su vida político-social y determina su organización institucional esencial».

Puede ser interesante detenerse algo en sus distintos elementos. Por lo que se refiere a, "acto o actos unilateral o unilaterales del Estado", con el uso de esta alternativa singular-plural se cumple con el a-formalismo, para no encorsetar demasiado la realidad constitucional en un determinado modelo formal como lo es la tradición continental, por oposición a la pluralidad de textos constitucionales del Derecho anglosajón. En cuanto a la necesidad de que la Constitución "conste por escrito", hay que destacar que esto supone un plus en cuanto a la forma que se exige para la generalidad de los actos unilaterales. En el campo de la Constitución no creemos honestamente que se pueda mantener que queda verdaderamente clara la existencia y el contenido de una Constitución si ésta no se refleja por escrito. También se dice que el Estado establece ciertos principios como rectores de su vida política, en otras palabras, que la Constitución es un acto de la voluntad de la comunidad política ${ }^{26}$, dado a sí misma, nunca impuesto. Los principios que se establecen como rectores de su vida político-social son los del Estado democrático y de derecho. No hay más Constitución que la democrática ${ }^{27}$. Por otro lado, la Constitución ha de recoger la organización institucional esencial del Estado. Al ser la Constitución auténtica norma normarum es necesario que recoja lo esencial de la distribución del poder entre los distintos órganos del Estado.

\section{LA CONSTITUCIÓN COMO ACTO UNILATERAL DEL ESTADO}

Esta es una de las principales novedades a las que da lugar la perspectiva que se utiliza. Para ver cómo se acomoda la Constitución a

26 PAINe (Los derechos del hombre, Madrid, 1984, pág. 192) «(...) una constitución no es el acto de un gobierno, sino de un pueblo que constituye un gobierno".

27 Es dentro de este mismo contexto de la lucha entre el ideario democrático y el liberal, donde se escucha la voz de MARX (Crítica a la Filosofía del Derecho del Estado de HEGEL, Méjico, 1968, pág. 42) colocándose al lado de la soberanía popular al decir, "(...) todas las formas de Estado tienen su verdad en la democracia". 
lo que el Derecho internacional concibe como actos unilaterales de los Estados hay que comparar el concepto de acto unilateral con el de Constitución. Siguiendo a DiEZ DE VELASCO ${ }^{28}$ entendemos por acto unilateral, "una manifestación de voluntad de un solo sujeto de Derecho internacional, cuya validez no depende prima facie de otros actos jurídi$\cos$ y que tiende a producir efectos para el sujeto que la emite y para terceros en determinadas circunstancias".

Se impone, pues, comparar elemento por elemento.

Primer elemento de los actos unilaterales de los Estados. La Manifestación de voluntad, su validez y sus requisitos.

Lo primero que se debe considerar es el contenido del acto unilateral del Estado, siendo esencial verificar su validez desde las perspectivas tanto interna como internacional. Por lo que se refiere a la validez de la constitución desde el Derecho interno no hay acto más válido y legítimo que una verdadera constitución. Ya que si recordamos el concepto substantivo de Constitución para el cual los valores del Estado democrático de derecho son esenciales, habremos de concluir que como no hay más legitimidad que la democrática, el supremo acto de legitimación se produce con el recurso al pueblo, cuya plasmación es precisamente la Constitución. Desde el Derecho internacional se produce una total remisión de éste a lo que dispongan los Derechos internos de los Estados, no entra por lo tanto en requisitos para la validez de la Constitución.

En segundo lugar, la doctrina internacionalista exige la concurrencia de otra serie de requisitos dentro de la manifestación de voluntad, se trata de la capacidad, el consentimiento y la forma.

La Capacidad. Ésta se debe ver en tres sentidos. El primero de ellos es el de la capacidad para ser sujeto activo de un acto unilateral, que debe entenderse que se tiene por el hecho de ser un Estado. El segundo, es el de la capacidad para expresar válidamente un acto unilateral. Aquí la cuestión requiere algo más de detenimiento, pero en esencia se debe acudir a la analogía con la convención de Viena de 1969 sobre derecho de los tratados que en su artículo 7 apartado 2, da "plenos poderes" sin necesidad de su presentación a "los jefes de Estado, jefes de gobierno y ministros de relaciones exteriores, para la ejecución de todos los actos relativos a la celebración de un tratado".

28 DízZ de VeLASCO, M., Instituciones de Derecho Internacional Público, Tomo I, Novena edic., Madrid 1991. 
Es a estos mismo sujetos a los que, como mínimo hay que otorgar la capacidad para emitir de manera válida actos unilaterales que vinculen a su Estado. Es decir, que se admite que estas personas representan válidamente a su Estado. La Constitución en su concepto substantivo emana del pueblo, que no es el representante sino el verdadero cuerpo donde reside la soberanía del Estado.

El consentimiento, o mejor dicho los posibles vicios de éste. Por lo que respecta al error y al dolo no son de interés para el caso que nos ocupa de la Constitución como acto unilateral del Estado ya que es inverosímil que se den. La violencia y la intimidación sí requieren, en cambio, consideración. Se trataría de aquellos actos unilaterales de los Estados, dictados bajo la amenaza o ejercicio efectivo de la fuerza, que habría que interpretar como nulos. Esto es perfectamente trasladable a una Constitución. No son difíciles de encontrar casos en los que una potencia amenazante o invasora ha impuesto una Ley fundamental. Así, en la historia de España habría que concluir que, desde esta perspectiva del Derecho internacional, la Carta de Bayona de 1808 era nula, ya que fue dictada por las autoridades francesas a una España que se encontraba militarmente ocupada por sus ejércitos, y cuyos máximos gobernantes se encontraban físicamente en su poder.

La forma. El Derecho internacional contemporáneo se caracteriza por su eminente a-formalismo, por lo que desde su punto de vista "la forma no es decisiva" ${ }^{29}$. De todos modos, hay que hacer una salvedad. Para los actos unilaterales de los Estados no es necesario ningún requisito formal especial, y la jurisprudencia ha dejado bien claro que lo importante es que conste la intención y la voluntad del Estado autor. Pues bien, en principio ello podría ser aplicable a la Constitución como acto unilateral, pero no lo es en toda su extensión. Para que en el ámbito del Derecho interno algo tan importante como son las reglas fundamentales por las que la comunidad política va a regir su vida en común queden expresadas de un modo que "su intención resulte claramente" ${ }^{30}$, es necesario que ello quede reflejado por escrito. Más arriba se ha recordado el concepto substantivo de Constitución que se está empleando, y que los principios del

${ }^{29}$ Caso de los ensayos nucleares franceses (Cour Internationale de Justice, Recueil, 1974, pags 267 y 268), cuando se dice: “(...) que una declaración sea verbal o escrita no implica ninguna diferencia esencial (...) la forma no es decisiva".

30 En expresión del Tribunal Internacional de Justicia en el caso del templo de Preah Vihear, Cour Internationale de Justice, Recueil, 1961, pág. 31. 
Estado democrático de derecho deben entenderse como los vertebradores de una Constitución que merezca tal nombre. Entre estos principios se encuentra el de la seguridad jurídica, que únicamente puede quedar garantizado si la norma normarum se encuentra recogida por escrito.

Segundo elemento de los actos unilaterales de los Estados. Emana de un único sujeto de Derecho internacional.

Se trata de un elemento que emana del mismo tenor literal del nombre de acto unilateral, y la traslación del requisito de que el acto unilateral emane de un único Estado a la esfera de la Constitución se plantea en principio de modo lineal, ya que la Constitución de un Estado, como emanación de su soberanía, se plantea como acto independiente y supremo, exponente de esta soberanía, y de este modo, se vendría a concluir que cuando hay Estado hay Constitución y que solamente puede emanar una Constitución de un Estado.

Tercer elemento de los actos unilaterales de los Estados. Su eficacia no depende de ningún otro acto jurídico.

Desde el Derecho internacional se exige que el valor jurídico del acto unilateral no emane de una fuente anterior que le dote de validez, sino que encierre en sí mismo todos los requisitos y elementos necesarios para su validez.

Por lo que se refiere al cumplimiento de este requisito por parte de la Constitución, se trata del elemento de más fácil comprobación. Las fuentes de legitimidad de la Constitución son pre-internacionales, y vienen determinadas por el mismo concepto de legitimidad. Además, hoy por hoy no cabe, ni puede caber, expresión de legitimidad que no tenga su origen en la soberanía popular. La Constitución española de 1978 , en el apartado segundo de su artículo 1, señala taxativamente que "La soberanía nacional reside en el pueblo español, del que emanan los poderes del Estado". De esta manera, y sin ulterior apelación posible, la Constitución en cuanto que fuente de fuentes, norma normarum, es quien se dota a sí misma de validez, sin recurso a otra norma o fuente superior a ella.

Cuarto elemento de los actos unilaterales de los Estados. Conlleva intención de obligarse por parte de su autor.

Por lo que se refiere al Derecho internacional, éste exige que conste la intención del Estado de comprometerse por medio del acto unilateral, por lo que se entra en un terreno resbaladizo, como lo es el de toda construcción jurídica en la que sea relevante el análisis de la intencionalidad. Pero tal dificultad probatoria no elimina en nada la 
necesidad de constatar la intencionalidad por parte del Estado que produce un acto unilateral.

Por lo que se refiere a la Constitución, ésta se establece como un proyecto de futuro por el que la comunidad política hace pública su voluntad de regular precisamente por esas bases su futura convivencia. Es evidente, pues, la intención de obligar de la Constitución, pero es interesante ver cómo es precisamente la Constitución, considerada en su concepto substantivo, la que da el paso de solamente obligar a obligarse, o como ha dicho Kaegi ${ }^{31}, "(\ldots)$ lo fundamentalmente nuevo del Estado constitucional frente a todo el mundo del autoritarismo, es la fuerza vinculante bilateral de la norma". Esta fuerza vinculante bilateral de la norma se configura, para García de Enterría ${ }^{32}$ como, "(...) la vinculación a la vez de las autoridades y de los ciudadanos, de todas las autoridades y de todos los ciudadanos, en contraposición a toda forma de Estado de privilegios de viejo y nuevo cuñon. Esta vinculación a la vez de los poderes $y$ de los ciudadanos es esencial en el constitucionalismo. Esto, que está muy claro en las relaciones ad intra, es decir, de fronteras para dentro, parecería complicarse si se predica ad extra, en las relaciones entre Estados. La diferencia fundamental estriba en que, mientras que en las primeras se está en una relación entre no-iguales, dado el poder coactivo del Estado sobre sus ciudadanos, en el caso de las relaciones entre Estados la existencia de un principio de ius cogens que establece la igualdad entre los Estados, parecería que hace más difícil su aplicación. Es bien cierto que, hoy por hoy, no existe una institución supra-estatal con poderes sobre los Estados equiparables a los que el Estado tiene sobre sus ciudadanos, pero ello no debe llevarnos a concluir que, puesto que puede no haber castigo, es que no hay Derecho.

En definitiva, la Constitución es un acto unilateral del Estado y como tal se integra en el sistema de fuentes del Derecho internacional, y por ello genera derechos y obligaciones no solamente para su autor sino también para terceros. Es más, a partir de ahora hay que considerar que la Constitución es otro ejemplo más de acto unilateral del Estado, por cuatro razones fundamentales.

31 KAEGI, Die Verfassung als rechtliche Grundordnung des Staates, Zürich, 1945 , págs. 41 y sgtes.

32 García de EnTERRÍA, E., La constitución como norma y el tribunal constitucional, Madrid, 1985, pág. 49. 
En primer lugar porque no cabe hablar de tipos o clases de actos unilaterales de los Estados -en ello coincide la doctrina internacionalista ${ }^{33}$-, sino solamente de ejemplos de actos unilaterales, $y$ al no ser categorias, ni ser una enumeración exhaustiva o numerus clausus, no tiene por qué haber problema en ampliar la lista de ejemplos de actos unilaterales de los Estados.

En segundo lugar, porque aunque a primera vista pudiera parecer que la Constitución se asemeja a otros ejemplos, no es así. La Constitución sólo podría ser considerada como reconocimiento si se retoma un concepto de Constitución que ya está en desuso. Sólo si aceptásemos como Constitución lo que Cánovas del Castillo entendía por tal, la Constitución escrita se manifestaría como el reconocimiento de la "Constitución interna", pero al haber adoptado el concepto substantivo de Constitución, ello deja de tener sentido. La notificación es el acto por el que se pone en conocimiento de un tercero un hecho, una situación, una acción o un documento, del que se pueden derivar efectos jurídicos, y que será en consecuencia considerado como jurídicamente conocido por aquél a quien se dirigió. De este concepto hay que extraer cada uno de sus elementos para comprobar si se ajustan a la Constitución. La Constitución es un acto, con lo que cumple con el primero. En la notificación se habla de su contenido diciendo que puede ser un hecho, un documento, etc... y la Constitución se plasma en uno o varios documentos. Se ha dicho también que la notificación es el acto por

33 La mayoría de la doctrina no establece una clasificación propiamente dicha de los actos unilaterales de los Estados, sino que se limita a una enumeración, más o menos extensa, según los casos, de una serie de ejemplos de éstos. Pero hay que destacar dos intentos clasificadores importantes, se trata de los de RousSEAU y los de Álvarez. Según la clasificación de Rousseau (Droit International Public, Tomme I, Introduction et Sources, Paris, 1970), no puede mantenerse que una categoría de los actos unilaterales de los Estados se cualifica porque cree obligaciones. El juez del Tribunal Internacional de Justicia de la Haya, Alejandro Álvarez (Le Droit international nouveau dans ses rapports avec la vie actuelle des peuples, Paris, 1959), ha desarrollado una clasificación propia, basándose en su propia opinión disidente en el caso HAYA DE LA TORRE (Tribunal Internacional de Justicia, caso sobre derecho de asilo, sentencia de 20 de noviembre de 1950. Recueil des Arrêts, Avis consultatifs et Ordonnances, 1950 , págs. 290 y 291). Si se presta atención a alguno de los tipos de actos unilaterales que establece el juez ÁlvarEZ, se verá que más que a categorías, los rótulos describen determinados ejemplos acaecidos en la práctica de las Relaciones Internacionales. Así, cuando habla de «f) los actos que los Estados de un continente tienen derecho a efectuar, y que deben ser respetados por los demás Estados en dicho continente", lo que realidad está queriendo decir es que procede a abrir una categoría de actos unilaterales de los Estados dentro de los que pueda incluirse el caso Haya de la Torre. 
medio del cual se pone su contenido en conocimiento de un tercero, $y$ es aquí donde se rompe el paralelismo entre Constitución y notificación. La esencia de la notificación es que "otro", más o menos definido, se dé por enterado de un determinado hecho, situación, acción o documento. No puede mantenerse que el objetivo esencial de la Constitución sea el de señalar al resto de la comunidad internacional el texto de la Constitución. Cosa distinta es que sí pueda notificarse una Constitución pero no que la Constitución en sí misma sea un ejemplo de notificación. Para ver si la Constitución puede ser calificada como una promesa hay que acudir a los elementos de ésta. Ambas comparten el ser una declaración unilateral de voluntad, y el conllevar el compromiso de adoptar un determinado comportamiento. Lo que separa ambas figuras es que, si la promesa se estructura en torno a criterios de compromiso frente a otro u otros, es decir en cánones de bilateralidad, la Constitución se erige como un compromiso, en primer lugar frente a sí mismo y, en segundo lugar, erga omnes, con lo que la bilateralidad esencial en la promesa no se cumple. Así, la Constitución no puede ser considerada como una promesa.

En tercer lugar, la Constitución es un acto unilateral del Estado porque en la práctica de los Estados la figura de la Constitución es un ejemplo plenamente consolidado. En el Derecho interno el concepto de trabajo de Constitución se configura con una serie de elementos substantivos y formales perfectamente delimitados por la doctrina constitucionalista. En el Derecho internacional parecería algo menos evidente, pero ello no obsta para que la comprobación sea también sencilla. Las distintas teorías internacionalistas que intentan explicar las relaciones entre el Derecho internacional y los Derechos internos, tratan de la figura de las constituciones de los Estados. Que el término "Constitución" se utilice de una manera tan fluída, significa que no se duda, que no hay controversia, sobre lo que debe entenderse por tal. Pero conviene no ofvidar que frente a este empleo "formalista" o "material" de la palabra Constitución, aquí se está usando el sentido "sustantivo" del término.

En cuarto y último lugar, la importancia de la Constitución exige que se le dedique un ejemplo dentro de los actos unilaterales de los Estados.

\section{LA CONSTITUCIÓN, AL SER ACTO UNILATERAL DEL ESTADO, ES UNA DE LAS FUENTES DEL DERECHO INTERNACIONAL}

Habiendo dejado claro que la Constitución puede ser considerada como un acto unilateral del Estado, de ello hay que extraer una con- 
secuencia inmediata, que es su configuración como una de la fuentes del Derecho internacional. Éstas vienen derivadas, en primer lugar por el tantas veces reiterado artículo 38 del Estatuto del Tribunal Internacional de Justicia ${ }^{34}$. En él se habla de las convenciones internacionales, es decir los tratados internacionales (entre los cuales no se puede considerar como tal la Constitución), de la costumbre internacional (donde tampoco cabe la Constitución), de los principios generales del Derecho, de las decisiones judiciales y de la doctrina (bajo ninguno de cuyos epígrafes puede entenderse que cabe la Constitución). Hasta aquí el artículo 38; ello no quiere decir que en él se encuentren todas las fuentes del Derecho internacional. La doctrina ${ }^{35}$ y la jurisprudencia internacionales han dejado bien claro el carácter no exhaustivo de esta enumeración. Por ello, la relación de las fuentes del Derecho internacional debe completarse con las resoluciones de las organizaciones internacionales y con lo que se conoce como los actos unilaterales de los Estados, que es donde entra la Constitución.

Por todo ello, es evidente que si la Constitución es un acto unilateral, provoca sus mismos efectos. Estos efectos son de dos clases, por un lado, los que se derivan para el autor $y$, por otro, aquellos para terceros.

En cuanto a los efectos de los actos unilaterales de los Estados para su autor, el fundamento de éstos se encuentra en un principio general del Derecho tan viejo como lo es la doctrina de los actos propios, que encuentra su expresión en el tan conocido, venire contra factum propium non valet. Pero también hay que hacer referencia al principio

34 Artículo 38, apartado 1 del Estatuto del Tribunal Internacional de Justicia, que determina:

«El Tribunal, cuya función es decidir conforme al Derecho Internacional las controversias que le sean sometidas, deberá aplicar: a) Las convenciones internacionales, sean generales o particulares, que establecen reglas expresamente reconocidas por los Estados litigantes. b) La costumbre internacional como prueba de una práctica generalmente aceptada como Derecho. c) Los principios generales del Derecho reconocidos por las naciones civilizadas. d) Las decisiones judiciales $y$ las doctrinas de los publicistas de mayor competencia de las distintas naciones como medio auxiliar para la determinación de las reglas de Derecho, sin perjuicio de lo dispuesto en el artículo 59 ".

${ }_{35}$ Hay unanimidad en la doctrina en lo que se refiere a considerar que el artículo 38 del estatuto del Tribunal Internacional de Justicia de la Haya no enumera la totalidad de las fuentes del Derecho internacional. Entre otros autores baste citar a Pastor RIDRUEJo (Curso de Derecho Internacional Público y Organizaciones Internacionales, Madrid, 1989), DíEz dE VELASCO ( Instituciones de Derecho Internacional Público, Tomo I, Pág. 100), Reuter (Derecho Internacional Público, Barcelona, 1984), RousSEAU (Droit International Public, Tomme I, Introduction et Sources, Paris, 1970), etc... 
de buena fe y a la doctrina del estoppel. El estoppel es una figura que tiene su origen en el derecho inglés y que ha sido recogida por el Derecho internacional. La figura del estoppe/ entra en juego para proteger a aquellos que hubieran actuado de buena fe, apoyándose legítimamente en la conducta o en las manifestaciones previas de otro sujeto. Respecto a las implicaciones del estoppe/ para la Constitución, el principio general es que si un determinado Estado ha actuado basándose en las declaraciones contenidas en la Constitución de otro Estado, y este último quiere volver atrás para dejar sin consecuencias lo que de otro modo serían efectos favorables para ese primer Estado, no podrá hacerlo en aplicación de la doctrina del estoppel.

Efectos de los actos unilaterales de los Estados para terceros. Aquí hay que partir desde la aplicación analógica de un principio general de Derecho internacional aplicado a los tratados, el de pacta tertiis nec nocent nec prossunt, que traspuesto a los actos unilaterales vendría a configurarse como acta tertiis nec nocent nec prossunt. Pero no se trata de un principio absoluto, sino que en ciertas ocasiones se quiebra, como en la del alcance de los artículos 2.2. y 103 de la Carta de las Naciones Unidas ${ }^{36}$, que aquilatan a su verdadera extensión este principio de los efectos relativos de los tratados. Por ello no tiene nada de extraño que igual fractura se produzca en el caso de los actos unilaterales de los Estados. Es esta capacidad de los actos unilaterales de los Estados para generar obligaciones a terceros que no han participado directamente en el proceso de creación de la norma, por medio de la figura de la aquiescencia ${ }^{37}$, lo que Morand ${ }^{38}$ ha denominado el poder heteronormativo de los actos unilaterales.

De este modo, la Constitución tiene unos efectos que hasta ahora no se le adscribian. Efectos que provienen de su condición de acto uni-

36 Carta de la Organización de las Naciones Unidas, artículo 2.2.- "La Organización hará que los Estados que no son miembros de las Naciones Unidas se conduzcan de acuerdo con estos principios en la medida que sea necesario para mantener la paz y la seguridad internacionales". Artículo 103.- "En el caso de conflicto entre las obligaciones contraídas por los Miembros de las Naciones Unidas en virtud de la presente Carta y sus obligaciones contraidas en virtud de cualquier otro convenio internacional, prevalecerán las obligaciones impuestas por la presente Cartan.

37 La aquiescencia es la figura por la que un Estado participa en la creación de una obligación para otro Estado. Por ella el Estado aquiescente manifiesta de modo tácito su voluntad, con lo que concurre a la formación y nacimiento de la obligación.

38 Morand, Ch. A., La législation dans les Communautés Européennes, París, 1969, págs. 29 a 53. 
lateral del Estado. Ello es lo que hemos denominado como el «alcance vinculante internacional" de la Constitución. La Constitución tiene dos tipos efectos. Por un lado los que se pueden denominar como winternos", y por otro, los "internacionales". Al hacer referencia a los efectos hay que dejar bien claro que la adjetivación de "interno" o «internacional», no se refiere al campo de actuación donde la Constitución despliega sus efectos, sino al origen de los efectos, es decir, si es el ordenamiento interno o el internacional el que otorga determinadas consecuencias a la Constitución.

Por lo que se refiere a los efectos «internos", el impacto fundamental de la Constitución en el ámbito interno, es decir en el ordenamiento jurídico interno de Estado, viene determinado por el principio de superlegalidad Constitucional. Estos efectos "internos" son ya clásicos en la evolución histórico-doctrinal de la Constitución.

Más novedosos son los que, desde aquí, se califican como efectos "internacionales" de la Constitución. De este alcance vinculante internacional hay que destacar los efectos que la Constitución produce para su Estado. El efecto esencial es la vinculación del Estado autor de la Constitución a lo que ha establecido en ella. Esta idea de vinculación al propio Derecho ya está plenamente consagrada de dos maneras. La primera de ellas se deriva del mismo concepto substantivo de Constitución que se está empleando, se trata de la necesidad de aplicar el principio de legalidad positivo o positif bindung. Por él, el Estado solamente puede actuar en aquello para lo que está expresamente habilitado, por lo que la sumisión de los Poderes Públicos, es decir del Estado, al Derecho debe de ser total y completa. La segunda es la propiamente internacional. La proclamación de la Constitución como un acto unilateral del Estado le predica a la primera los efectos de estos últimos. La figura mediante la cual el Derecho internacional adscribe efectos a los actos unilaterales de los Estados para el Estado autor es el ya mencionado estoppel, donde hay que considerar tres momentos diferentes. En primer lugar se produce una acto unilateral por parte de un Estado, que aqui es la Constitución. La Constitución produce una modificación esencial en el entorno jurídico del Estado que se dota a sí mismo de una Constitución, ya que ésta no afecta solamente a las obligaciones internacionales del Estado sino a todas, absolutamente todas, las obligaciones de ese Estado. En un segundo momento, se produce una conducta por parte de otro sujeto de Derecho internacional, que se basa en el estado de cosas que ha producido el acto unilateral del primer Estado. Se produce una actuación basándose precisamente en las disposiciones constitucionales del otro Estado considerado. Por último, 
se produce otro acto del primer Estado que tiende a volver a la situación previa a la creada por el primer acto unilateral que emanó de él. Es precisamente en este momento donde tiene sentido la aplicación de la doctrina del estoppel, pues se trata de proteger al segundo Estado que obró de buena fe.

En definitiva, al quedar un Estado constituído, erga omnes, como Estado democrático de Derecho, y al ser su Constitución fuente de Derecho internacional, determina que si este Estado vuelve atrás, es decir que produce una serie de actos inconstitucionales para revocar su propio régimen constitucional, al hacer esto último estará yendo no sólo contra su constitución como norma interna, sino que estará contraviniendo una norma internacional. Ya se sabe que todo ilícito internacional (es decir toda violación de una norma de Derecho internacional) da lugar a responsabilidad internacional en el sujeto que la violó. Así pues, la ruptura del propio régimen constitucional, al constituir una violación del Derecho internacional, debe dar lugar a la responsabilidad internacional del Estado.

Aquí únicamente nos interesa considerar la responsabilidad internacional derivada del delito internacional lato sensu, puesto que la responsabilidad derivada de un hecho lícito es completamente ajena al estudio de la Constitución como acto unilateral del Estado, ya que lo que aquí es relevante es la responsabilidad que se deriva de una violación de la Constitución, por lo tanto de la comisión de un hecho ilícito internacional ${ }^{39}$.

Terminando con esta cualificación de la responsabilidad hay que. dejar bien sentado que, si bien la violación per se de la Constitución no es un crimen internacional, entendido éste como la violación de una norma de Derecho internacional de ius cogens; si la violación de la Constitución ha llevado aparejadas las violaciones de alguno de los principios esenciales de la comunidad internacional, entonces, quedaría configurada como crimen internacional. Pero lo que le atribuye tal naturaleza no es la violación en sí misma de la Constitución sino la violación de un principio esencial contenido en la Constitución, por lo que no se puede predicar la traslación automática de la figura del crimen internacional a la violación de la Constitución.

39 Proyecto de Artículos sobre Responsabilidad del Estado, Comisión de Derecho Internacional, Naciones Unidas, 1973. Artículo 3.- "There is an internationally wrongful act of a State when: a) conduct consisting of an action or omission is attribuable to the State under international law; and b) that conduct constitutes a breach of an international obligation of the State». 
Ahora hay que pasar a la puesta en práctica de la responsabilidad internacional del Estado por la violación de su propia Constitución. Hay que recordar que las violaciones globales de la constitución son el caso que se estudia, ya que las concretas o parciales exigen un estudio pormenorizado de cada caso particular que hace imposible una consideración en conjunto.

También hay que tener siempre presentes las repercusiones que para las posibles medidas concretas tiene la actual estructura de la sociedad internacional. En primer lugar, señalar la dicotomía que a veces se observa entre oportunidad política y juridicidad de las acciones ${ }^{40}$; también recordar que los Estados verdaderamente constitucionales siguen siendo, seguimos siendo, una minoría, con lo que intentar que una comunidad internacional donde la mayoría son Estados incluso contrarios a este modelo se involucre en la defensa del Estado democrático de derecho puede parecer ilusorio. Además la sociedad internacional se basa en un principio sobre el cual no puede haber acuerdo con el Derecho constitucional. Para el Derecho internacional todos los Estados son iguales, mientras que para el constitucional los que son iguales son los individuos ${ }^{41}$.

A continuación se expone toda una panoplia de medidas que se pueden adoptar por la comunidad internacional en respuesta a la autoviolación de la propia Constitución por parte de un Estado.

En cuanto a los "medios no-jurídicos o políticos», son aquellas medidas que puede tomar el Estado que se siente afectado por esta violación del Derecho internacional $y$ que no precisan de una argumentación jurídica previa. Los ejemplos que se ofrecen son infinitos, entre los que basta citar la llamada a consultas del embajador acreditado en ese país, la no presentación de cartas credenciales de un nuevo embajador ante un Gobierno al que se considera como ilegítimo, la retirada del embajador ante ese país, la expulsión del embajador del país que ha violado, etc...

40 Zemanek (Responsabilité internationale, Paris, 1987, pág. 81 y sgtes.), apunta muy acertadamente que el mundo del Derecho y el de lo que califica como el de la "oportunidad política", no coinciden siempre.

${ }^{41}$ En el Derecho internacional un luxemburgués cuenta tanto como 2.287 hindues. Si el voto en la esfera internacional de la India y de Luxemburgo tiene el mismo valor, es que sus respectivas poblaciones, en principio, tienen el mismo peso. Un fácil cálculo nos lleva a la conclusión que exponemos: si la población de la India es de 896.597 .000 personas y la de Luxemburgo de 392.000 la conclusión de la división es precisamente la que se expone. 
Los "medios jurídicos", es decir, aquéllos que para su utilización requieren de la existencia de una causa jurídica previamente establecida que le legitime para tomar estas medidas, entre los que hay que mencionar los siguientes.

Primero. La generalización de la "doctrina Bethancourt", que prevé la ruptura de las relaciones diplomáticas con aquél Estado que haya violado su Constitución hasta que ésta sea restablecida.

Segundo. La suspensión y/o terminación de los tratados vigentes, que es una conclusión lógica de ser considerada la Constitución como un acto unilateral del estado, ya que la propia Convención de Viena de 1969 sobre derecho de los tratados prevé como causa de suspensión o terminación de un tratado el incumplimiento de las obligaciones de éste por una de las partes.

Se podría argumentar que el incumplimiento de la propia Constitución no es lo mismo que un incumplimiento de las obligaciones que emanan de ese mismo tratado, que es el supuesto que contempla la Convención de Viena, pero si entendemos que la condición de ser un Estado constitucional está implícita en los compromisos hechos por los Estados en el tratado, y que además es «una disposición esencial para la consecución del objeto y fin del tratado", tal y como venimos sosteniendo, entonces tal problema queda salvado. Esta idea de sobreentender que el tratado se firma con otro Estado "constitucional" puede ser, en muchos casos, difícil de justificar, pero hay un tipo de tratados en los que no puede entenderse de otro modo. Se trata de aquéllos que implican una relación íntima y estrecha en el campo político y/o militar, que hace que sea una condición indispensable para su funcionamiento el que los regímenes políticos de los respectivos Estados sean similares. Esta necesidad de similitud entre las partes firmantes no es algo nuevo, ni siquiera privativo de los tratados firmados entre países que cuentan con una verdadera Constitución. De este mismo modo habría que entender una cláusula de homogeneidad de regímenes en el tratado firmado el 29 de julio de 1940 entre la España del general Franco y el Portugal de Oliveira Salazar, o el de 27 de septiembre del mismo año entre el Japón Tojo, la Italia de Mussolini y la Alemania Nacional-socialista de Hitler.

Tercero. La suspensión y/o expulsión como miembro de una organización internacional.

Dentro de este mismo ámbito se encuentran aquellos tratados internacionales que dan lugar al nacimiento de organizaciones internacionales que expresamente determinan que entre sus miembros sólo 
pueden haber Estados democráticos o que entre sus objetivos está la defensa de las libertades y de la democracia. Ejemplo de ello es la Organización del Tratado del Atlántico Norte, creada por el tratado de Washington de 4 de abril de 1949, que en su Preámbulo establece que, "Las Partes en este Tratado: (...) Determinados a salvaguardar las libertades de sus pueblos, su herencia común y su civilización, basadas en los principios de democracia, libertades individuales e imperio del derecho, (...)». De igual modo el Consejo de Europa ${ }^{42}$, que también en su Preámbulo, dice: «Reafirmando su adhesión a los valores espirituales y morales que son patrimonio común de los pueblos y la verdadera fuente de libertad individual, la libertad política y el imperio del derecho, principios sobre los cuales se funda toda auténtica democracian. Artículo 1.b).- "(...) por la salvaguardia y la mayor efectividad de los derechos humanos y las libertades fundamentales". O la propia Unión Europea ${ }^{43}$, donde hay que hacer referencia a tres documentos. Por un lado, a la declaración común del Parlamento Europeo, del Consejo y de la Comisión sobre los derechos fundamentales de 5 de abril de 1977. Por otro, a la declaración del Consejo Europeo de Copenhague de 8 de abril de 1978 en la que se "(...) declara solemnemente que el respeto de la democracia representativa y de los derechos humanos, así como su mantenimiento en cada uno de los Estados miembros, son elementos esenciales de la pertenencia a las Comunidades". Y también, en términos muy parecidos, la Declaración solemne del 19 de junio de 1983 sobre la Unión Europea. Siguiendo con este último caso, también es importante destacar la práctica internacional llevada a cabo por la propia Unión Europea en lo que a acuerdos de Asociación y de Amistad y Cooperación se refiere, en los que o bien se incluye expresamente lo que se denomina como "cláusula democrática", o bien se entiende que está implícita. Por medio de ella se interpreta que el tratado se aplica si, y sólo si, el Estado, o los Estados, que firman con la Unión Europea mantienen su régimen democrático, o lo que es lo mismo, y utilizando la terminología que hemos usado a lo largo de todo el artículo, si se mantienen como Estados "constitucionales".

Nada impide pues que, entendiendo como implícita esta "cláusula democrática", y basándose en que la violación de su Constitución está configurada como un delito internacional stricto sensu, el Estado constitucional aplique como contramedida la suspensión, o incluso la marzo de 1957.

42 Consejo de Europa, tratado de Londres de 5 de mayo de 1949.

43 Tratados CECA de 18 de abril de 1951, CEE y EURATOM ambos de 25 de 
terminación, de aquellos tratados internacionales cuyo contenido y/o aplicación sea incompatible con la existencia de un régimen no constitucional por parte de su otro interlocutor, con lo que daría lugar a la suspensión de la condición de miembro y, en su caso, expulsión de la organización internacional, de aquel Estado que ingresó siendo «constitucional” y que ya no lo es.

\section{Cuarto, y último. El recurso a la vía judicial internacional.}

Por lo que se refiere al ius standi para reclamar hay que decir exactamente lo mismo que del derecho a aplicar contramedidas, es decir, que la legitimación activa para reclamar el cumplimiento de la Constitución la tiene, en principio, cualquier Estado. Incluso este ius standi activo habría que predicarlo de los Estados no constitucionales que "contratan" con un Estado constitucional. Ciertamente aquí se daría la paradoja de ver cómo un Estado autoritario o de inspiración comunista, reclama ante los tribunales internacionales que un Estado democrático cumpla con su propia Constitución, que contiene los principios del Estado democrático de derecho. Precisamente unos principios que el Estado reclamante rechaza y combate en su vida política interna. Pero esta aparente contradicción no tiene por qué extrañar, ya que la vida jurídica y más concretamente la judicial, está llena de este tipo de casos, en los que el reclamante exige el cumplimiento de una contraprestación que él no estaría dispuesto a aplicarse. Por lo que se refiere al ius standi pasivo, o derecho a ser llevado ante los tribunales internacionales por la violación de la propia Constitución, basta con ser Estado verdaderamente constitucional, pues no olvidemos que sólo estos pueden violar una verdadera Constitución, nadie puede romper lo que no tiene.

Los problemas se plantean inmediatamente después, sobre todo en lo que se refiere a la competencia de un tribunal internacional en concreto y al posible contenido de la reparación. En cuanto a la competencia del tribunal, habría que estar a las reglas generales de competencia de cada instancia judicial internacional en concreto, pero hay que decir que el "tribunal natural" sería el Tribunal Internacional de Justicia. Es en este sentido en el que habría que interpretar lo dispuesto en el Estatuto del Tribunal Internacional de Justicia ${ }^{44}$, que establece en su artículo 36: 1. "La competencia de la Corte se extiende a todos los litigios que las partes le sometan y a todos los asuntos especialmente previstos en la Carta de las Naciones Unidas o en los tratados $y$

44 Estatuto del Tribunal Internacional de Justicia que figura anejo a la Carta de las Naciones Unidas, San Francisco, 1945. 
convenciones vigentes". 2. "Los Estados partes en el presente Estatuto podrán declarar en cualquier momento que reconocen como obligatoria ipso facto y sin convenio especial, respecto a cualquier otro Estado que acepte la misma obligación, la jurisdicción de la Corte en todas las controversias de orden jurídico que versen sobre: a) la interpretación de un tratado; b) cualquier cuestión de derecho internacional; c) la existencia de todo hecho que, si fuera establecido, constituiria una violación de una obligación internacional; d) la naturaleza o extensión de la reparación que ha de hacerse por el quebrantamiento de una obligación internacional». Del tenor literal de este artículo queda clara la posibilidad de sumisión de las cuestiones relacionadas con la violación de la propia Constitución a través de lo dispuesto tanto por el apartado primero, como por el párrafo d) del apartado segundo. De todos modos, también es evidente que la jurisdicción y competencia del Tribunal Internacional de Justicia está supeditada al reconocimiento de la misma por parte de los Estados, lo que dificulta y limita su acción.

Por lo que respecta al contenido de la reparación, éste puede ser muy variado, y puede ir desde la exigencia de una mera declaración pública, hasta el resarcimiento de daños y perjuicios. Y es precisamente en este último inciso donde surgen los problemas, ya que la cuantificación de los daños producidos por la violación de la Constitución es algo muy difícil de hacer. Pero aún así, recurriendo a la analogía con el Derecho interno donde está ya consagrada como práctica habitual la compensación pecuniaria, incluso por el fallecimiento de un ser humano, esto podría trasponerse al orden internacional. No es que la muerte tenga un precio, ni que el conculcar la propia Constitución lo tenga, pero sí es posible valorar los perjuicios e intentar compensarlos en la medida en que ello sea posible. La cuestión del cuánto y el cómo, es algo que, por el momento, debe quedar abierto para cada caso concreto.

Otro aspecto importante son las consecuencias en la formación de la voluntad internacional de los Estados. La división de poderes, o lo que es lo mismo en una formulación doctrinalmente más moderna y correcta, el control mutuo entre poderes, es una necesidad para poder ser calificado como Estado democrático de derecho. Por ello, la intervención de una pluralidad de poderes en la formulación de la voluntad exterior del Estado en materia de tratados se traslada de ser una exigencia meramente interna, impuesta al tener una verdadera Constitución, a ser una exigencia del ordenamiento internacional, al ser la Constitución también una fuente del propio Derecho internacional.

Otra consecuencia importante es la necesaria adecuación de todo tratado internacional a la Constitución. Se trata de otra implicación de 
ser un Estado democrático de derecho, concretamente de la separación de poderes que se acaba de ver y del carácter de superlegalidad. Es indispensable en toda verdadera Constitución substantiva, y consiste en la necesaria interpretación de todo tratado de acuerdo con la Constitución. Como ya se ha visto, la Convención de Viena de 1969 sobre derecho de los tratados, en sus artículos 27 y $46^{45}$, establece que la violación del Derecho interno no exime del incumplimiento de un tratado, a menos que la violación del Derecho interno fuese manifiesta y de una norma de importancia fundamental. Así y todo, si un tratado hubiese sido firmado y hubiese entrado en vigor, cumpliendo con todos los requisitos formales que la Constitución establece para ello, pero que al final la instancia competente de interpretación constitucional lo declarase inconstitucional, entendemos que no cabría deducir de ello responsabilidad internacional para el Estado. Ello porque cuando un Estado, sea de la naturaleza que sea, se liga internacionalmente por medio de un tratado con un Estado constitucional, ha de entenderse que lo hace asumiendo y conociendo las obligaciones que emanan para el Estado constitucional de ser precisamente eso, un Estado constitucional, $y$ dentro de estas obligaciones se encuentra el que todo su ordenamiento sea conforme a su Constitución, lo que incluye también a los tratados internacionales, bajo sanción de declaración de nulidad por parte de la instancia competente para ello. De este modo, debe entenderse que se trata de la firma de un acuerdo internacional bajo la existencia implícita de una condición resolutoria. En el caso de que finalmente se declarase la no concordancia del tratado con la Constitución, el otro Estado ya sabía de esta posibilidad, por lo que este último no podría invocar los artículos 27 y 46 de la Convención de Viena de 1969, ya que aquí no se está usando la violación del derecho interno como excusa

45 Convención de Viena de 1969 sobre derecho de los tratados:

Artículo 27. "El Derecho interno y la observancia de lo tratados". "Una parte no podrá invocar las disposiciones de su Derecho interno como justificación del incumplimiento de un tratado. Esta norma se entenderá sin perjuicio de lo dispuesto en el artículo $46 \%$.

Artículo 46. "Disposiciones de Derecho interno concernientes a la competencia para celebrar tratados». Apartado 1. «EI hecho de que el consentimiento de un Estado en obligarse por un tratado haya sido manifestado en violación de una disposición de su Derecho interno concerniente a la competencia para celebrar tratados no podrá ser alegado por dicho Estado como vicio de su consentimiento, a menos que esa violación sea manifiesta y afecte a una norma de importancia fundamental de su Derecho interno". Apartado 2. "Una violación es manifiesta si resulta objetivamente evidente para cualquier Estado que proceda en la materia conforme a la práctica usual y de buena fe". 
para el incumplimiento de un tratado, sino que se está aduciendo la aplicación de una regla internacionalizada. La Constitución ya no es Derecho interno, es fuente de Derecho internacional, por lo que su aplicación no debe seguir los estrechos márgenes que para el Derecho interno establecen los artículos mencionados de la Convención de 1969. Otro sería el caso, si hubiese por parte del Estado constitucional mala fe o engaño, en cuya circunstancia habría que acudir a un procedimiento internacional judicial o arbitral para determinar las consecuencias.

\section{NUEVAS OBLIGACIONES DE TODO ESTADO CONSTITUCIONAL EN SU CONDUCTA INTERNACIONAL}

Debido a todo lo que hasta ahora se ha dicho, a partir de ahora hay que entender que el Estado constitucional queda ligado por su Constitución, no solamente frente a su propio pueblo, sino también frente al resto de la comunidad internacional. De este modo los derechos recogidos en una verdadera Constitución quedan protegidos de una doble manera, una, que es la tradicionalmente recogida por el Derecho interno, en la que la Constitución se presenta como garantía de la libertad de los ciudadanos. Y la segunda, que es la novedosa, que consiste en que los derechos que predica para sus ciudadanos quedan también tutelados por el Derecho internacional.

Por lo que respecta a cómo la Constitución determina la forma de actuar del Estado en la esfera internacional, lo primero que hay que abordar son los condicionamientos de conducta; en otras palabras, las mayores obligaciones de los Estados verdaderamente constitucionales precisamente derivadas del hecho de serlo. Desde el punto de vista del Derecho interno es evidente que ser un Estado constitucional supone asumir toda la panoplia de limitaciones y controles que para la acción de los poderes públicos supone el ser un Estado de derecho. Desde el punto de vista del Derecho internacional es un principio de ius cogens el de la igualdad de todos los Estados; pues bien, esta igualdad se puede ver desde dos puntos de vista. Desde el lado de los derechos es evidente que ello es así, pero desde el lado de las obligaciones queremos manifestar que los Estados constitucionales tienen un plus de obligaciones, por un argumento esencial: se trata de la necesaria congruencia entre los principios vertebradores de índole interna y su actuación externa. Sostener que los principios del Estado democrático y de derecho sólo afectan a la esfera interna del Estado es separar radicalmente la actuación ad intra y ad extra del Estado, estableciendo una 
esquizofrenia que es de difícil justificación, y que, además, iría en contra de la unidad esencial del Derecho, del ordenamiento jurídico tomado en su conjunto. Por mucho que en la práctica internacional, abunden los ejemplos de una total dicotomía entre los medios usados en política exterior e interior, no es menos cierto que se trata de un doble rasero, que progresivamente encuentra menos defensores y menor justificación.

\section{NUEVAS OBLIGACIONES DE TODO ESTADO CONSTITUCIONAL EN SU EVOLUCIÓN Y/O REFORMA CONSTITUCIONAL}

Hay que volver a considerar ciertos problemas que plantea la revocabilidad de la Constitución una vez vista su dimensión internacional. Dentro de este ámbito hay dos parámetros a considerar, el primero de ellos es, siguiendo a Paine ${ }^{46}$, que "la vanidad y la presunción de gobernar desde más allá de la tumba es la más ridícula de todas las tiranías", y el segundo es que al hablar de cambio constitucional se hace referencia a una situación concreta que es el paso desde un régimen constitucional o otro que puede serlo o no. La situación de partida es la posesión de una verdadera Constitución, ya que, como «no hay otra Constitución que la Constitución democrática», un régimen no democrático no puede reformar o cambiar lo que no tiene.

La "reforma jurídica" hace referencia a aquellos casos en los que se introducen reformas totales o parciales al texto constitucional vigente, por los procedimientos establecidos en éste. Si se llevase al absurdo el argumento de la Constitución como acto unilateral del Estado y como tal fuente de Derecho internacional, cabría pensar que para su reforma seria necesario el concurso de la voluntad del resto de los Estados. Nada más lejos de la realidad, ya que la Constitución es acto unilateral en su conjunto, lo que significa que también lo son las reglas de reforma que en ella se contienen, por lo que si éstas se respetan, no hay contradicción ni problema alguno. Un caso distinto sería el paso, por los medios de reforma establecidos en la Constitución, de un régimen constitucional a otro no democrático. Se produce un respeto de la letra, pero no el espíritu de la Constitución, se pasa de una situación de Constitución a una de no-Constitución, ocultando bajo la apariencia de una reforma o cambio "jurídico" lo que en realidad es un cambio radi-

PAINE, Los derechos del hombre, Madrid, 1984, 
cal. La respuesta aquí es que hay que admitir la posibilidad de este cambio basándose en consideraciones, en primer lugar de tipo jurídico-formal, ya que se ha respetado el procedimiento constitucional, pero también de tipo doctrinal ya que una generación no tiene poder para ligar a las demás hasta el fin de los tiempos.

Por lo que respecta a la "reforma no juridica", ésta es aquélla que no sigue los cauces procedimentales establecidos en la constitución vigente del Estado en cuestión; se trata pues de un acto revolucionario no jurídico. Pero ello no significa que el Derecho no pueda entrar a considerarlo, sino que es precisamente el Derecho quien debe suministrarnos las pautas para poder analizarlo. También hay que recordar que, al tratarse de la conculcación de una Constitución, lo que se viola es la norma suprema de un Estado democrático de derecho, o en otras palabras que ya de por sí este acto carece de legitimidad, ya que hoy por hoy sólo cabe afirmar que existe una única legitimidad, la que emana del pueblo, la democrática. De este modo, un acto que vaya en contra de una verdadera Constitución supone un cambio anti-jurídico. Por ello, la violación de la propia Constitución, es decir el cambio constitucional revolucionario, supone el nacimiento de la responsabilidad internacional para el Estado que lo comete.

La siguiente gran cuestión es cómo la consideración de la Constitución como acto unilateral del Estado actúa en forma de límite a la libertad de elección de "régimen político" por los Estados. Lo primero que surge aquí es una aparente contradicción entre un principio general de ius cogens internacional recogido en la Declaración sobre los Deberes y Derechos de los Estados ${ }^{47}$, que dispone en su artículo 1 que "todo Estado tiene derecho a la independencia $y$, por ende, a ejercer libremente todas sus facultades legales, inclusive la de elegir su forma de Gobierno, sin sujección a la voluntad de ningún otro Estadon. Pero pese a esta "flagrante» contradicción hay que ir más allá en el análisis, primero viendo el alcance real de esta libertad de elección de régimen, seguidamente viendo el criterio de interpretación histórico, siguiendo con los límites que tiene todo derecho, para terminar perfilando correctamente cómo limita la consideración de la Constitución como acto unilateral del Estado la libertad de elección de régimen político para un Estado.

47 Declaración sobre los Deberes y Derechos de los Estados, aprobada por la Asamblea General de las Naciones Unidas por la Resolución 375 IV, de 6 de diciembre de 1949. 
Por lo que se refiere al alcance de esta libertad de elección de régimen político, lo primero que hay que decir es que en el artículo 1 de la Declaración sobre los Derechos y los Deberes de los Estados se menciona la expresión "forma de gobierno", lo que a primera vista puede parecer muy claro, pero no es así, ya que si se aplica la terminología constitucionalista interna, por forma de gobierno habría que entender, "el complejo de instrumentos que se articulan para conseguir finalidades estatales $y$, por lo tanto, los elementos que miran a la titularidad y ejercicio de las funciones soberanas atribuídas a los órganos constitucionales" ${ }^{48}$. De modo que resulta claro que no es a ésto a lo que quiere referirse el mencionado artículo 1. Mientras que por forma de Estado "se entiende, convencionalmente, el conjunto de elementos que caracterizan, globalmente, a un ordenamiento referido particularmente a finalidades planteadas como objetivos de acción de los órganos constitucionales", y es precisamente esto lo que, sin duda, quiere decir.

En segundo lugar esta libertad de elección se predica frente a otros Estados. Lo que se busca es proteger al Estado de la intromisión ilegítima de otro Estado, por lo que el fin esencial de este artículo 1 no coincide con el posible ámbito de aplicación que se daría en el caso de la Constitución.

También hay que señalar el criterio de interpretación histórico, es decir, hay que contextualizar la Declaración sobre los Derechos y los Deberes de los Estados en su fecha, el 6 de diciembre de 1949, en pleno auge de la guerra fría. Entonces surgió este compromiso entre Occidente $y$ el Este, consistente en el establecimiento de un principio que permitiese que cada bloque se sintiese seguro de sus conquistas y no se viese amenazado por la expansión de su contrario. De este modo, si se reconocía que todo régimen político era, en principio, válido, se privaba de base ideológica a aquellas maniobras o intentos de derrocarlo, era una consagración del statu quo para evitar la Tercera Guerra Mundial. Pero hoy en día es evidente que nos encontramos en una situación internacional muy distinta, más incierta, por la ausencia de reglas fijas, pero también más segura y más libre. Donde antes eran de aplicación principios que evitaban la guerra hoy estos mismos principios pueden no tener sentido, que es precisamente lo que le ocurre aquí. Así, basta aplicar la cláusula rebus sic stantibus para dar cabida a la interpretación que proponemos.

48 De Vergottinni, G., Derecho Constitucional Comparado, Madrid, 1983, pág. 102. 
Por último hay que hablar de los límites que tiene todo derecho, ya que la configuración de los derechos como la concesión de potestades ilimitadas es algo ya plenamente superado tanto en el ámbito interno como internacional. $Y$ es dentro de este último donde surgen dos ejemplos que muestran la concepción limitadora de los derechos en aras de la protección de bienes jurídicos superiores. Por un lado hallamos el Derecho internacional de los Derechos Humanos, y por otro, la ya mencionada con anterioridad "doctrina Bethancourt".

Por lo que se refiere al Derecho internacional de los Derechos Humanos, si bien es cierto que aún está en su fase de constitución y que es seriamente disputado a nivel político y práctico, no es menos cierto que su existencia e importancia se abre paso entre las concepciones jurídicas modernas. En palabras del artículo 1 de la Resolución adoptada el 13 de septiembre de 1989 por el Instituto de Derecho Internacional sobre la protección los derechos humanos y el principio de no intervención en los asuntos internos de los Estados, "los derechos humanos son la expresión directa de la dignidad de la persona humana». La obligación de los Estados de asegurar su respeto se desprende del propio reconocimiento de esta dignidad que ya proclaman la Carta de las Naciones Unidas y la Declaración Universal de Derechos Humanos. El Instituto de Derecho Internacional concluye estableciendo que "esta obligación internacional es, según una fórmula utilizada por la Corte Internacional de justicia, una obligación erga omnes que incumbe a todo Estado con respecto a la comunidad internacional en su conjunto $y$ todo Estado tiene un interés jurídico en la protección de los derechos humanos (...)".

La llamada "doctrina Bethancourt». Lo primero que hay que señalar es que aún no se encuentra más que esbozada como posibilidad $y$, por el momento, no ha sido plenamente adoptada por ningún Estado. Se refiere a la actitud a tomar por parte de la comunidad internacional a la hora de hacer frente a un cambio revolucionario en el régimen político de un Estado. Concretamente se trata de legitimar a la comunidad internacional para que, en el caso de producirse dentro de un Estado un golpe contra su régimen constitucional, se puedan tomar medidas contra este hecho, para posibilitar la vuelta de este Estado al sistema constitucional derrocado. Esta doctrina, discutida en el seno de la Organización de Estados Americanos a raíz del golpe de Estado en Haití de 1991, prevé la ruptura de relaciones diplomáticas en el caso de producirse en un Estado un golpe de estado que dé lugar a un gobierno de facto.

Estos dos ejemplos señalan una dirección hacia la que parece encaminarse el Derecho internacional, $y$ es precisamente en este mismo 
sentido al que apunta la tesis esencial que hemos mantenido, que la Constitución debe entenderse, desde la esfera del Derecho internacional, como un acto unilateral del Estado, y que como tal es una de las fuentes del mismo y, por ello, despliega toda una serie de efectos, tanto para su autor como para otros sujetos de la comunidad internacional. 